\title{
Studies on Synthesis and Spectral Characterization of Some Transition Metal Complexes of Azo-Azomethine Derivative of Diaminomaleonitrile
}

\author{
C. Anitha, ${ }^{1}$ C. D. Sheela, ${ }^{2}$ P. Tharmaraj, ${ }^{3}$ and R. Shanmugakala ${ }^{3}$ \\ ${ }^{1}$ Department of Chemistry, Fatima Michael College of Engineering and Technology, Madurai 625 020, India \\ ${ }^{2}$ Department of Chemistry, The American College, Madurai 625 002, India \\ ${ }^{3}$ Department of Chemistry, Thiagarajar College, Madurai 625 009, India
}

Correspondence should be addressed to P. Tharmaraj; sheelatharmaraj@gmail.com

Received 30 September 2012; Accepted 2 December 2012

Academic Editor: Wei-Yin Sun

Copyright (C) 2013 C. Anitha et al. This is an open access article distributed under the Creative Commons Attribution License, which permits unrestricted use, distribution, and reproduction in any medium, provided the original work is properly cited.

New complexes of 2,3-bis(5-(4-chlorophenyl)diazenyl)-2-hydroxybenzylideneamino)maleonitrile (CDHBDMN) with VO(II), $\mathrm{Mn}(\mathrm{II}), \mathrm{Co}(\mathrm{II}), \mathrm{Ni}(\mathrm{II}), \mathrm{Cu}(\mathrm{II})$, and $\mathrm{Zn}$ (II) were synthesized and characterized by analytical and physicochemical techniques, that is, elemental analyses, molar conductivity, UV, IR, EPR, ${ }^{1} \mathrm{H}$-NMR spectra, magnetic susceptibility and also by aid of scanning electron microscopy (SEM), nonlinear optical study (NLO), fluorescence spectral studies, and solvatochromic behaviors. Electronic and magnetic susceptibility measurements of the complexes indicate square pyramidal geometry for VO(II), octahedral for Ni(II), and square planar geometry for all the other complexes. The EPR spectral data provide information about their structures on the basis of Hamiltonian parameters and the degree of covalency. These metal complexes were also tested for their antibacterial and antifungal activities to assess their inhibiting potential. Metal-mediated fluorescence enhancement is observed on complexation of the azo Schiff base ligand. The synthesized compounds were investigated for nonlinear optical properties, and the surface morphology of the $\mathrm{Cu}(\mathrm{II})$ complex was studied by scanning electron microscopy.

\section{Introduction}

Schiff base ligands derived from the condensation of salicylaldehyde with diamines and their complexes $[1,2]$ played an important part in the development of inorganic chemistry, as widely studied coordination compounds are increasingly important as biochemical, analytical, and antimicrobial reagents $[3,4]$. Also they have been used as antibacterial, antifungal, anticancer, antitubercular, hypertensive, and hypothermic reagents [5, 6]. Tetrameric HCN (diaminomaleonitrile, DAMN), a diamine, is one of the most versatile reagents in organic chemistry, used as a precursor for producing nucleotides and for synthesizing a wide variety of heterocyclic compounds $[7,8]$.

Their great potential has recently been demonstrated in the synthesis of conjugated linear polymers [9], in the thermostable optical material industry [10], and widely employed in the fluorescent dye industry [11].
Interestingly, coordination chemistry of azo Schiff bases derived from DAMN is not well explored. Only a few well-characterized complexes of DAMN-based ligands are known to us. Maclachlan et al. [12] for the first time reported the crystal structures of Schiff base derived from DAMN and salicylaldehyde with some metal complexes. A novel bisazomethine Schiff base formed by the condensation of 3-hydroxyquinoxaline-2-carboxaldehyde and 2,3diaminomaleonitrile has been carried out by Arun et al. [13]. The studies revealed that the compound exists in two major tautomeric forms and the Schiff base exhibits positive absorption and fluorescent solvatochromism and displays dual fluorescence with large stoke shifts. Rajasekar et al. [14] have investigated $\mathrm{Ni}(\mathrm{II})$ and $\mathrm{Cu}(\mathrm{II})$ metal complexes derived from salicylaldehyde/5-methylsalicylaldehyde and diaminomaleonitrile (DAMN). In their work antibacterial activity was investigated and square planar geometry was proposed for $\mathrm{Ni}(\mathrm{II})$ and $\mathrm{Cu}(\mathrm{II})$ complexes. 
Azo compounds are very important molecules and have attracted much attention in both academic and applied research [15-20]. Our interest in this molecule stems from its ability to act as a diamine and also from the fact that the electron-withdrawing $\mathrm{CN}$ groups affect the coordinating capacity of DAMN itself and have the potential to modulate the electronic properties of resulting coordination complexes and also their chemical reactivity. Hence the present work deals with the synthesis and characterization of the azo Schiff base ligand 2,3-bis(5-(4-chlorophenyl)diazenyl)-2hydroxybenzylideneamino)maleonitrile (CDHBDMN) and its $\mathrm{VO}(\mathrm{II}), \mathrm{Mn}(\mathrm{II}), \mathrm{Co}(\mathrm{II}), \mathrm{Ni}(\mathrm{II}), \mathrm{Cu}(\mathrm{II})$, and $\mathrm{Zn}(\mathrm{II})$ complexes. Photoluminescence, nonlinear optical properties, biological activity, electrochemical behavior, and solvatochromic behaviors of the azo compound and its complexes are also examined.

\section{Experimental}

The chemical used for the synthesis purpose is used as such, and the common solvents used at various stages of this work are purified according to the standard procedures described in Weissenburg series [21]. Elemental analyses were carried out using a Perkin-Elmer 2400 II elemental analyzer. Molar conductance of the complexes was measured in DMSO at room temperature using a Systronic Conductivity Bridge 304. Magnetic susceptibility of the complexes was performed on a Sherwood MSB mark1 Gouy balance. Infrared spectral studies were carried out on a Shimadzu FT IR 8000 spectrophotometer using $\mathrm{KBr}$ discs. UV-Vis spectra were obtained using a THERMO SPECTRONIC 6 HEXIOS $\alpha$ and fluorescence spectra were determined with an ELICO SL174 spectrofluorometer. ${ }^{1} \mathrm{H}$-NMR spectra were recorded on Bruker DRX-300, $300 \mathrm{MHz}$ NMR spectrometer using TMS as reference. EPR spectrum of $\mathrm{Cu}$ (II) complex was recorded in Varian E-112 machine at 300 and $77 \mathrm{~K}$ using TCNE (tetracyanoethylene) as the g-marker. Cyclic voltammetric measurement for $\mathrm{VO}$ (II) and $\mathrm{Cu}$ (II) complexes in DMSO was carried out on an electrochemical analyzer $\mathrm{CH}$ Instruments (USA) using a three-electrode cell containing an $\mathrm{Ag} / \mathrm{AgCl}$ reference electrode, $\mathrm{Pt}$ wire auxiliary electrode, and glassy carbon working electrode with tetrabutylammonium perchlorate as supporting electrolyte. Electron ionization (EI) mass spectra were recorded by JEOL-GC Mass Spectrometer MATE-2. The second harmonic generation (SHG) conversion efficiency of the Schiff base ligand was determined by the modified version of powder technique in IISc, Bangalore, and the SEM images were recorded using JEOL-JSM-840 a scanning electron microscopy at Karunya Deemed University, Coimbatore.

2.1. Synthesis of 2,3-Bis(5-(4-chlorophenyl)diazenyl)-2hydroxybenzylideneamino)maleonitrile (CDHBDMN)s. An ethanolic solution $(20 \mathrm{~mL})$ of 5-((4-chlorophenyl)diazenyl)2-hydroxybenzaldehyde (CPDAHB) [22] (2.6 g, $10 \mathrm{mmol})$ was added to an ethanolic solution of diaminomaleonitrile (DAMN) (0.54 g, $5 \mathrm{mmol})$. The solution mixture was refluxed with a few drops of glacial acetic acid as catalyst for $8 \mathrm{~h}$. The resulting brown solution was cooled in ice to give brown precipitate, which was collected by filtration and dried under vacuum. Recrystallization from absolute ethanol gave brown solid. The overall yield varied between $60 \%$ and $70 \%$. The scheme of the ligand is depicted in (Figure 1).

2.2. Synthesis of Metal(II) Complexes. To a solution of (1.48 g, $10 \mathrm{mmol}) \quad 2,3$-bis(5-(4-chlorophenyl)diazenyl)-2hydroxybenzylideneamino)maleonitrile (CDHBDMN) in $20 \mathrm{~mL}$ ethanol, $(10 \mathrm{mmol})$ of metal chlorides/sulphates $(\mathrm{M}=$ $\mathrm{VOSO}_{4} \cdot 2 \mathrm{H}_{2} \mathrm{O}, \mathrm{MnCl}_{2} \cdot 4 \mathrm{H}_{2} \mathrm{O}, \mathrm{CoCl}_{2} \cdot 6 \mathrm{H}_{2} \mathrm{O}, \mathrm{NiCl}_{2} \cdot 6 \mathrm{H}_{2} \mathrm{O}$, $\mathrm{CuCl}_{2} \cdot 2 \mathrm{H}_{2} \mathrm{O}$, and $\mathrm{ZnCl}_{2}$ ) were added. The solution was refluxed at $40-50^{\circ} \mathrm{C}$ with constant stirring for $1 \mathrm{~h}$, and the resulting solution was refrigerated for one day. The complexes were precipitated by adding petroleum ether. The colored complexes were filtered and washed with hot water and with ethanol and dried under vacuum. The yield obtained was 60-77\% (Figure 2).

\section{Results and Discussion}

The complexes have been characterized by IR, UV-visible, ${ }^{1} \mathrm{H}-\mathrm{NMR}$, EI-mass, EPR spectra, magnetic susceptibility measurements, and molar conductance. The analytical data of the ligand and the complexes together with their physical properties are given in Table 1. Based on the physicochemical characteristics, it was found that the air stable, moisture insensitive metal(II) complexes are soluble in chloroform and other common organic solvents. Analytical data are in good agreement with calculated values, as expected for the assigned formula, [ML], where $\mathrm{M}=\mathrm{VO}(\mathrm{II}), \mathrm{Mn}(\mathrm{II}), \mathrm{Co}(\mathrm{II}), \mathrm{Cu}(\mathrm{II})$, and $\mathrm{Zn}(\mathrm{II})$ and $\left[\mathrm{ML}\left(\mathrm{H}_{2} \mathrm{O}\right)_{2}\right]$ for $\mathrm{Ni}(\mathrm{II})$ complex; $\mathrm{L}=$ azo Schiff base. All the complexes show 1:1 metal-ligand stoichiometry and are nonhygroscopic in nature. The ligand behaves as tetradentate, and the metals are coordinated through oxygen and nitrogen donor atoms. The molar conductance values of mononuclear complexes in DMSO $\left(1 \times 10^{-3} \mathrm{M}\right)$ suggest the absence of ionic character.

3.1. Mass Spectral Studies. The mass spectra of azo Schiff base and its complexes were recorded at room temperature, and they are used to compare their stoichiometry composition. The azo Schiff base shows a molecular ion peak at $592 \mathrm{~m} / \mathrm{z}$. The molecular ion peak for the copper(II) complex observed at $653 \mathrm{~m} / z$ confirms the stoichiometry of metal chelates as $[\mathrm{ML}]$ type. It is also supported by the mass spectra of the other complexes, whereas nickel(II) complex shows molecular ion peak at $684 \mathrm{~m} / z$ confirming $\left[\mathrm{MLCl}_{2}\right]$ type. The mass spectral data support the structures of mononuclear transition metal complexes. The isotopic peaks from chlorine atom are identified at the mass spectra of the all compounds. The mass spectra of the ligand and its copper(II) complex are shown in Figure S1 (See Supplementary Material available online at doi:http://dx.doi.org/10.1155/2013/436275).

3.2. IR Spectral Studies. The IR spectra provide valuable information regarding the nature of functional group attached to the metal atom. In order to study the binding 


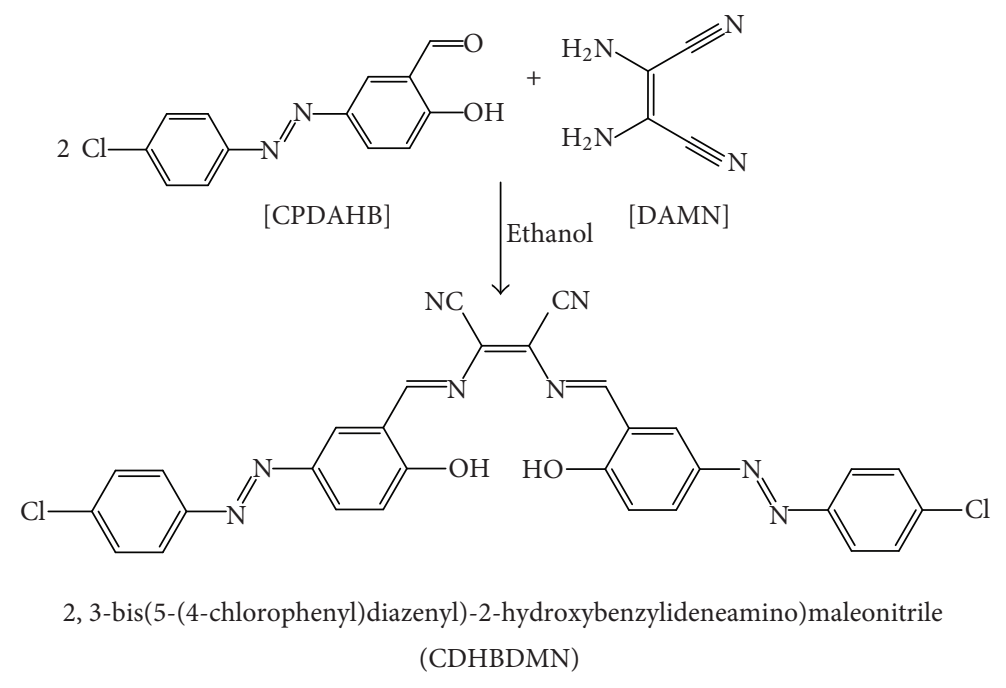

FIGURE 1: Synthesis of azo Schiff base ligand (CDHBDMN).

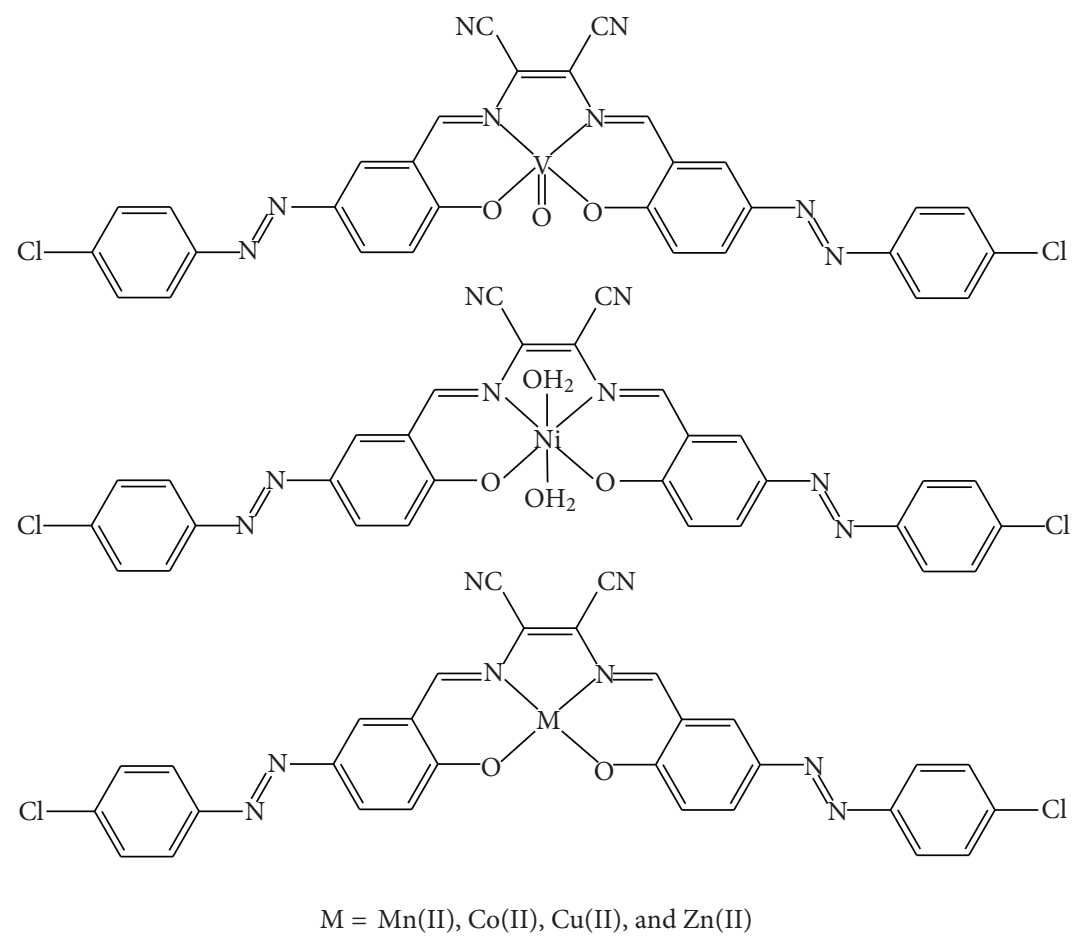

Figure 2: Structure of the metal(II) complexes of CDHBDMN. 
TABLE 1: Physical characterization, analytical, and molar conductance data of the ligand (CDHBDMN) and its metal(II) complexes.

\begin{tabular}{|c|c|c|c|c|c|c|c|}
\hline \multirow{2}{*}{ Compound } & \multirow{2}{*}{$\begin{array}{c}\text { FW } \\
\mathrm{g} / \mathrm{mol}^{-1}\end{array}$} & \multicolumn{4}{|c|}{ Found (Calcd) (\%) } & \multirow{2}{*}{ m.p. $\left({ }^{\circ} \mathrm{C}\right)$} & \multirow{2}{*}{$\begin{array}{c}\Lambda_{M} \\
\left(\Omega^{-1} \mathrm{~cm}^{2} \mathrm{~mol}^{-1}\right)\end{array}$} \\
\hline & & M & $\mathrm{C}$ & $\mathrm{H}$ & $\mathrm{N}$ & & \\
\hline $\begin{array}{l}\mathrm{C}_{30} \mathrm{H}_{18} \mathrm{Cl}_{2} \mathrm{~N}_{8} \mathrm{O}_{2} \\
(\mathrm{CDHBDMN})\end{array}$ & 592 & - & $\begin{array}{c}60.74 \\
(60.72)\end{array}$ & $\begin{array}{c}3.05 \\
(3.06)\end{array}$ & $\begin{array}{c}18.87 \\
(18.88)\end{array}$ & $229-231$ & - \\
\hline$[\mathrm{VO}(\mathrm{CDHBDMN})]$ & 657 & $\begin{array}{c}7.76 \\
(7.74)\end{array}$ & $\begin{array}{c}54.74 \\
(54.73)\end{array}$ & $\begin{array}{c}2.44 \\
(2.45)\end{array}$ & $\begin{array}{c}17.01 \\
(17.02)\end{array}$ & $276-278$ & 9.0 \\
\hline$[\mathrm{Mn}(\mathrm{CDHBDMN})]$ & 645 & $\begin{array}{c}8.52 \\
(8.50)\end{array}$ & $\begin{array}{c}55.73 \\
(55.75)\end{array}$ & $\begin{array}{c}2.53 \\
(2.50)\end{array}$ & $\begin{array}{c}17.33 \\
(17.34)\end{array}$ & $289-291$ & 10.3 \\
\hline$[\mathrm{Co}(\mathrm{CDHBDMN})]$ & 649 & $\begin{array}{c}9.08 \\
(9.06)\end{array}$ & $\begin{array}{c}55.43 \\
(55.41)\end{array}$ & $\begin{array}{c}2.47 \\
(2.48)\end{array}$ & $\begin{array}{c}17.24 \\
(17.23)\end{array}$ & $301-303$ & 9.5 \\
\hline$\left[\mathrm{Ni}(\mathrm{CDHBDMN}) \cdot 2 \mathrm{H}_{2} \mathrm{O}\right]$ & 684 & $\begin{array}{c}8.52 \\
(8.55)\end{array}$ & $\begin{array}{c}52.52 \\
(52.51)\end{array}$ & $\begin{array}{c}2.95 \\
(2.94)\end{array}$ & $\begin{array}{c}16.31 \\
(16.33)\end{array}$ & $298-300$ & 7.9 \\
\hline$[\mathrm{Cu}(\mathrm{CDHBDMN})]$ & 653 & $\begin{array}{c}9.72 \\
(9.70)\end{array}$ & $\begin{array}{c}55.03 \\
(55.01)\end{array}$ & $\begin{array}{c}2.44 \\
(2.46)\end{array}$ & $\begin{array}{c}17.12 \\
(17.11)\end{array}$ & $311-313$ & 7.4 \\
\hline$[\mathrm{Zn}(\mathrm{CDHBDMN})]$ & 654 & $\begin{array}{c}9.95 \\
(9.96)\end{array}$ & $\begin{array}{c}54.87 \\
(54.86) \\
\end{array}$ & $\begin{array}{c}2.47 \\
(2.46)\end{array}$ & $\begin{array}{c}17.04 \\
(17.06)\end{array}$ & $302-304$ & 6.2 \\
\hline
\end{tabular}

mode of the ligand to metal in the complexes, the IR spectrum of the free ligand was compared with the corresponding metal complexes. Selected vibrational bands of the ligand and its metal complexes are listed in Table 2, and the IR spectra of the ligand and $\mathrm{Ni}$ (II) complex are given in Figures S2a and S2b. The band at $1631 \mathrm{~cm}^{-1}$ is characteristic of the azomethine nitrogen in the free ligand. The lowering in this frequency to $1602-1620 \mathrm{~cm}^{€ 1}$ in all the complexes indicates involvement of the azomethine nitrogen in coordination with metal [23]. The ligand shows $v(\mathrm{O}-\mathrm{H})$ at $3289 \mathrm{~cm}^{-1}$, and the disappearance of this peak in spectra of all complexes indicates that chelation takes place via the phenolic $\mathrm{OH}$ and for nickel complex a broad variable band at $3981 \mathrm{~cm}^{-1}$ is attributed to $\mathrm{OH}$ of the coordinated water molecules.

For the complexes bands at $515-542 \mathrm{~cm}^{-1}$ could be assigned $v(\mathrm{M}-\mathrm{O})$. Other weak bands around lower frequency $473-495 \mathrm{~cm}^{-1}$ could be assigned to $v(\mathrm{M}-\mathrm{N})$ [24]. A strong band at $1282 \mathrm{~cm}^{-1}$ in the free azo Schiff base has been assigned to phenolic $\mathrm{C}-\mathrm{O}$ stretch. Upon complexation, this band displaces to higher frequency $\left(1303-1330 \mathrm{~cm}^{-1}\right)$ indicating coordination through phenolic oxygen [25]. In ligand and all the complexes bands at $2233-2242 \mathrm{~cm}^{-1}$ are assigned to $v(-\mathrm{C} \equiv \mathrm{N})$ [26]. The sharp band at $1492 \mathrm{~cm}^{-1}$ is assigned to the stretching vibration of the diazo group of the ligand and the infrared spectra of the complexes did not show any frequency shift of the $-\mathrm{N}=\mathrm{N}$ - band, which may be explained by nonparticipation in complex formation [27]. In addition to other bands, the vanadyl complex shows the characteristic $\mathrm{V}=\mathrm{O}$ asymmetric stretching frequency at $940 \mathrm{~cm}^{-1}$. These data are well in accordance with those of reported complexes.

3.3. ${ }^{1} H$-NMR Spectral Studies. The ${ }^{1} \mathrm{H}$ NMR spectra of the azo Schiff base and its zinc(II) complex in DMSO- $\mathrm{d}_{6}$ were recorded. The two hydroxyl groups and azomethine groups are in equivalent environment in the present ligand and its complexes. The ${ }^{1} \mathrm{H}$ NMR spectrum of the Schiff base ligand shows the following signals: phenyl as multiplets at 6.8 to $7.9 \delta$, the peak at $10.0 \delta$ is attributable to the phenolic $-\mathrm{OH}$ group present in the salicylaldehyde moiety, and the azomethine proton $(\mathrm{C}-\mathrm{CH}=\mathrm{N}-)$ appears at $8.2 \delta$. Zinc complex shows that the phenolic $-\mathrm{OH}$ is involved in complexation due to the disappearance of the signal at $10.0 \delta$. The azomethine proton signal in the spectrum of the zinc complex is shifted downfield compared to the free ligand, suggesting deshielding of the azomethine group due to the coordination with metal ion. There is no appreciable change in all of the other signals of this complex.

3.4. Electronic Spectral and Magnetic Susceptibility Studies. The electronic absorption spectra of the ligand and its complexes were recorded in DMSO at $300 \mathrm{~K}$. The absorption spectra of the ligand show strong peaks at 25125 and $29069 \mathrm{~cm}^{-1}$ which were assigned to the $-\mathrm{N}=\mathrm{N}-$ azo group and $-\mathrm{CH}=\mathrm{N}-$ groups of the azo Schiff base ligand, respectively. The spectral data of the ligand and its complexes are given in Table 3.

The absorption spectrum of vanadyl(II) complex shows absorption at 12345 and $20120 \mathrm{~cm}^{-1}$ due to ${ }^{2} \mathrm{~B}_{2} \rightarrow{ }^{2} \mathrm{E}$ and ${ }^{2} \mathrm{~B}_{2} \rightarrow{ }^{2} \mathrm{~B}_{1}$ transitions consistent with that of square pyramidal geometry, and the same is further confirmed from its magnetic moment value of 1.76 B.M. [28]. The electronic absorption spectrum of cobalt(II) complex shows absorption at $15748 \mathrm{~cm}^{-1}$, which may be tentatively assigned to ${ }^{2} \mathrm{~A}_{1 \mathrm{~g}} \rightarrow$ ${ }^{2} \mathrm{~B}_{2 \mathrm{~g}}$ transition. The spectrum resembles those reported for square planar cobalt(II) complexes [29], and the effective magnetic moment of the cobalt(II) complex is 2.51 B.M. corresponding to the square-planar stereochemistry around $\mathrm{d}^{7}$ cobalt(II) ion [30].

Nickel(II) complex exhibited three absorption bands at 10989,17636 , and $23041 \mathrm{~cm}^{-1}$ and may be tentatively 
TABLE 2: IR spectral data $\left(\mathrm{cm}^{-1}\right)$ of CDHBDMN and its metal(II) complexes.

\begin{tabular}{|c|c|c|c|c|c|c|}
\hline Compound & $v(\mathrm{C} \equiv \mathrm{N})$ & $v(\mathrm{CH}=\mathrm{N})$ & $v(\mathrm{C}-\mathrm{O})$ & $v(\mathrm{~N}=\mathrm{N})$ & $v(\mathrm{M}-\mathrm{O})$ & $v(\mathrm{M}-\mathrm{N})$ \\
\hline$(\mathrm{CDHBDMN})$ & 2242 & 1631 & 1282 & 1402 & - & - \\
\hline$[\mathrm{VO}(\mathrm{CDHBDMN})]$ & 2233 & 1611 & 1317 & 1401 & 530 & 485 \\
\hline$[\mathrm{Mn}(\mathrm{CDHBDMN})]$ & 2240 & 1620 & 1315 & 1403 & 510 & 473 \\
\hline$[\mathrm{Co}(\mathrm{CDHBDMN})]$ & 2237 & 1602 & 1303 & 1400 & 542 & 493 \\
\hline$\left[\mathrm{Ni}(\mathrm{CDHBDMN}) \cdot 2 \mathrm{H}_{2} \mathrm{O}\right]$ & 2239 & 1610 & 1320 & 1402 & 516 & 480 \\
\hline$[\mathrm{Cu}(\mathrm{CDHBDMN})]$ & 2241 & 1606 & 1309 & 1401 & 515 & 478 \\
\hline$[\mathrm{Zn}(\mathrm{CDHBDMN})]$ & 2240 & 1604 & 1330 & 1400 & 540 & 495 \\
\hline
\end{tabular}

TABLE 3: Electronic spectral data of CDHBDMN and its metal(II) complexes.

\begin{tabular}{|c|c|c|c|c|}
\hline Compound & $\begin{array}{c}\lambda_{\max }\left(\mathrm{cm}^{-1}\right) \\
\varepsilon\left(\mathrm{L} \mathrm{mol}^{-1} \mathrm{~cm}^{-1}\right)\end{array}$ & Transition & Geometry & $\mu_{\text {eff }}($ B.M.) \\
\hline \multirow{2}{*}{ (CDHBDMN) } & $25125(2002)$ & ILCT $^{*}$ & \multirow{2}{*}{-} & \multirow{2}{*}{-} \\
\hline & $29069(4490)$ & ILCT & & \\
\hline \multirow{2}{*}[\mathrm{VO}(\mathrm{CDHBDMN})]{} & $12345(152)$ & ${ }^{2} \mathrm{~B}_{2} \rightarrow{ }^{2} \mathrm{E}$ & \multirow{2}{*}{ Square pyramidal } & \multirow{2}{*}{1.76} \\
\hline & $20120(280)$ & ${ }^{2} \mathrm{~B}_{2} \rightarrow{ }^{2} \mathrm{~B}_{1}$ & & \\
\hline$[\mathrm{Co}(\mathrm{CDHBDMN})]$ & $15748(182)$ & ${ }^{2} \mathrm{~A}_{1 \mathrm{~g}} \rightarrow{ }^{2} \mathrm{~B}_{2 \mathrm{~g}}$ & Square planar & 2.51 \\
\hline \multirow{3}{*}[\mathrm{Ni}(\mathrm{CDHBDMN})\cdot(\mathrm{H}_{2}\mathrm{O})_{2}]{} & $10989(216)$ & ${ }^{3} \mathrm{~A}_{2 \mathrm{~g}}(\mathrm{~F}) \rightarrow{ }^{3} \mathrm{~T}_{2 \mathrm{~g}}(\mathrm{~F})$ & \multirow{3}{*}{ Octahedral } & \multirow{3}{*}{3.15} \\
\hline & $17636(210)$ & ${ }^{3} \mathrm{~A}_{2 \mathrm{~g}}(\mathrm{~F}) \rightarrow{ }^{3} \mathrm{~T}_{1 \mathrm{~g}}(\mathrm{~F})$ & & \\
\hline & $23041(279)$ & ${ }^{3} \mathrm{~A}_{2 \mathrm{~g}}(\mathrm{~F}) \rightarrow{ }^{3} \mathrm{~T}_{1 \mathrm{~g}}(\mathrm{P})$ & & \\
\hline$[\mathrm{Cu}(\mathrm{CDHBDMN})]$ & $18903(240)$ & ${ }^{2} \mathrm{~B}_{1 \mathrm{~g}} \rightarrow{ }^{2} \mathrm{~A}_{1 \mathrm{~g}}$ & Square planar & 1.87 \\
\hline
\end{tabular}

assigned as ${ }^{3} \mathrm{~A}_{2 \mathrm{~g}}(\mathrm{~F}) \rightarrow{ }^{3} \mathrm{~T}_{2 \mathrm{~g}}(\mathrm{~F}),{ }^{3} \mathrm{~A}_{2 \mathrm{~g}}(\mathrm{~F}) \rightarrow{ }^{3} \mathrm{~T}_{1 \mathrm{~g}}(\mathrm{~F})$, and ${ }^{3} \mathrm{~A}_{2 \mathrm{~g}}(\mathrm{~F}) \rightarrow{ }^{3} \mathrm{~T}_{1 \mathrm{~g}}(\mathrm{P})$ transitions indicating the octahedral geometry of the complex.

The value of the various ligand field parameters $10 \mathrm{Dq}, \mathrm{B}$, $\beta, \beta^{\circ}$, and $\nu_{2} / \nu_{1}$ was calculated to be $10989 \mathrm{~cm}^{-1}, 314 \mathrm{~cm}^{-1}$, $0.30,69$, and 1.6 . The covalent factor $\beta$ equal to $\mathrm{B} / \mathrm{B}^{\prime}$ for the complex is less than one suggesting considerable amount of covalent character of the metal-ligand bonds. The energy separation between ${ }^{3} \mathrm{~A}_{2 \mathrm{~g}}(\mathrm{~F})$ and ${ }^{3} \mathrm{~T}_{2 \mathrm{~g}}(\mathrm{~F})$ is equal to $10 \mathrm{Dq}$ and the values of $10 \mathrm{Dq}$, in octahedral $\mathrm{Ni}$ (II) complexes vary between 6400 and $12700 \mathrm{~cm}^{-1}$, depending on the position of the ligand in the spectrochemical series. The $10 \mathrm{Dq}$ value of the present nickel(II) complex is $10989 \mathrm{~cm}^{-1}$ which is the characteristic of octahedral geometry. The magnetic moment value 3.15 B.M. for $\mathrm{Ni}$ (II) complex supports the suggested geometry around the $\mathrm{Ni}$ (II) ion [31]. The molar intensity of nickel complexes is in the range of $210-279 \mathrm{~L} \mathrm{~mol}^{-1} \mathrm{~cm}^{-1}$.

The electronic spectrum of the copper(II) complex under study exhibits absorption band at $18903 \mathrm{~cm}^{-1}$, tentatively assigned to ${ }^{2} \mathrm{~B}_{1 \mathrm{~g}} \rightarrow{ }^{2} \mathrm{~A}_{1 \mathrm{~g}}$ transition which is the characteristic of square planar geometry. The magnetic moment of the copper(II) complex is 1.87 B.M. and is also supportive of square planar geometry [32]. The $\mathrm{Mn}$ (II) complex has a high spin magnetic moment of 5.29 B.M., expected for a $\mathrm{d}^{5}$ system with five unpaired electrons [33]. The magnetic moment of the zinc(II) complexes does not show any vibrational peak in the visible region which indicates the diamagnetic behavior of the complexes.
3.5. Electrochemical Behavior. The electrochemical properties of $\mathrm{VO}(\mathrm{II})$ and $\mathrm{Cu}(\mathrm{II})$ complexes have been investigated by cyclic voltammetry. Tetrabutylammoniumperchlorate (TBAP) was used as supporting electrolyte. The cyclic voltammogram (Figure S3) of $\mathrm{Cu}$ (II) complex $\left(1 \times 10^{-3} \mathrm{M}\right)$ in $\mathrm{DMSO}$ at the $100 \mathrm{mVs}^{-1}$ scan rate shows a well-defined redox process corresponding to the formation of the $\mathrm{Cu}(\mathrm{II}) / \mathrm{Cu}(\mathrm{I})$ couple at $E_{\mathrm{pa}}=0.562 \mathrm{~V}$ and the associated cathodic peak at $E_{\mathrm{pc}}=0.145 \mathrm{~V}$. This couple is found to be irreversible with $\Delta E_{\mathrm{p}}\left(E_{\mathrm{pa}}-E_{\mathrm{pc}}\right)=417 \mathrm{~V}$. The result was verified by varying the scan rates with peak potentials. Table S1 infers that the $E_{\mathrm{pc}}$ and $E_{\mathrm{pa}}$ values with different scan rates and the difference in the value of $E_{\mathrm{pa}}-E_{\mathrm{pc}}$ are larger than the value required for a reversible process $(59 \mathrm{mV})$ which indicates that the electron transfer process is irreversible [34]. The oxovanadium [35] complex exhibited two-step oxidation peaks at $0.223 \mathrm{~V}$ and $0.661 \mathrm{~V}$ and one reduction peak at $-0.702 \mathrm{~V}$. The redox process involves $\mathrm{V}(\mathrm{IV}) \rightarrow \mathrm{V}(\mathrm{III}) \rightarrow$ $\mathrm{V}(\mathrm{II}) \rightarrow \mathrm{V}(\mathrm{IV})$.

3.6. EPR Spectral Studies. The spin Hamiltonian parameters of the $\mathrm{Cu}$ (II) complex are listed in Table 4. The observed spectral parameters show anisotropic EPR spectra with $g_{\|}(2.10)>g_{\perp}(2.06)>g_{\mathrm{e}}(2.0023)$ is a characteristic of square-planar geometry [36], and the $g_{\text {iso }}$ (2.07) value less than 2.3 indicates the covalent character of the metal-ligand bond. The $\alpha^{2}$ value for the present complex of 0.79 indicates appreciable the in-plane covalency. The magnetic moment 
TABLE 4: EPR spectral parameters of [Cu(CDHBDM)].

\begin{tabular}{|c|c|c|c|c|c|c|c|c|c|c|c|c|}
\hline Compound & $g_{\|}$ & $g_{\perp}$ & $g_{\text {iso }}$ & $\alpha^{2}$ & $\beta^{2}$ & $\begin{array}{c}A_{\|} x \\
10^{4} \mathrm{~cm}^{-1}\end{array}$ & $\begin{array}{c}A_{\perp} x \\
10^{-4} \mathrm{~cm}^{-1}\end{array}$ & $\begin{array}{c}A_{\text {iso }} x \\
10^{-4} \mathrm{~cm}^{-1} \\
\end{array}$ & $\begin{array}{c}g_{\|} / A_{\|} \\
\mathrm{cm}\end{array}$ & $K_{\|}$ & $K_{\perp}$ & $\mu$ (B.M.) \\
\hline$[\mathrm{Cu}(\mathrm{CDHBDM})]$ & 2.10 & 2.06 & 2.07 & 0.79 & 0.95 & 195 & 56 & 103 & 107.6 & 0.98 & 0.69 & 1.87 \\
\hline
\end{tabular}

of the copper(II) complex calculated using the relation $\mu^{2}=$ $3 / 4|g|^{2}$ is 1.87 B.M., indicative of an unpaired electron. The orbital reduction factors $K_{\|}$and $K_{\perp}$ are estimated and, for this complex, $K_{\|}(0.98)>K_{\perp}(0.69)$ indicates poor in-plane $\pi$-bonding which is also reflected in $\beta^{2}$ value [37]. The EPR spectrum of the copper complex is shown in Figure 3.

3.7. Biological Studies. The ligands and their metal complexes were tested for their antibacterial and antifungal activities by well diffusion method [38]. Four bacterial stains (Staphylococcus aureus, Escherichia coli, Pseudomonas aeruginosa, Pseudomonas putida, Bacillus subtilis) were incubated for $24 \mathrm{~h}$ at $37^{\circ} \mathrm{C}$, and fungal stains (Aspergillus niger, Aspergillus flavus, and Rhizoctonia bataicola) were incubated for $48 \mathrm{~h}$ at $37^{\circ} \mathrm{C}$. Standard antibacterial drug, Streptomycin, was also screened under similar conditions for comparison. The fungi were subcultured in potato dextrose agar medium, and the standard antifungal drug, Nystatin, was used for control. Stock solution $\left(10^{-3} \mathrm{M}\right)$ was prepared by dissolving the compounds in DMSO. Antimicrobial activity studies were performed in triplicate, and the average was taken as the final reading. The growth of inhibition zones after incubation is summarized in Table S2.

The result of the microbial data (Figures 4(a), 4(b), and $4(c)$ ) indicates that some of the metal complexes exhibit higher antibacterial activity as compared to the free ligand. The increase in antimicrobial activity may be considered in light of Searl's concept and Tweedy's chelation theory [39]. The antimicrobial results evidently show that the activity of the Schiff base becomes more pronounced when it is coordinated to the metal ions. The structure of the tested compounds seems to be the principal factor influencing the antimicrobial activity. $\mathrm{Co}(\mathrm{II}), \mathrm{Cu}(\mathrm{II})$, and $\mathrm{Zn}$ (II) complexes were found to have better activity against all the microbial species, probably due the axial symmetry (square planar) in DMSO solution.

This enhancement in the activity may be rationalized on the basis of their structures, mainly possessing electron withdrawing groups chlorine and $-\mathrm{C} \equiv \mathrm{N}$. It has been suggested that the Schiff base with nitrogen and oxygen donor systems inhibits enzyme activity, since the enzymes which require these groups of their activity appear to be especially more susceptible to deactivation by metal ions on coordination. Tisseh and coworkers synthesized 5-substituted $1 \mathrm{H}-$ tetrazoles and observed the positive antimicrobial activity of its complexes against all species of Gram-positive and Gramnegative bacteria and fungi $[40,41]$.

3.8. Fluorescence Studies. The photoluminescence properties of azo Schiff base ligand and its metal complexes were studied at room temperature in DMSO. The emission spectrum

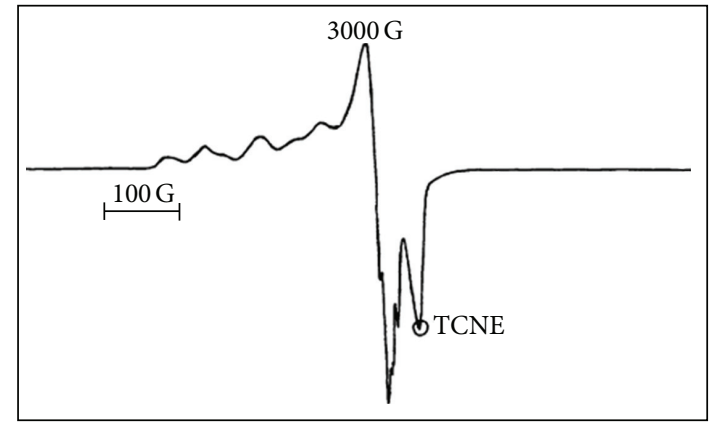

FIgURE 3: EPR spectrum of [Cu(CDHBDM)].

of the ligand excited at $361 \mathrm{~nm}$ shows an emission peak at $359 \mathrm{~nm}$. The metal complexes show strong fluorescence with moderate quantum yield which is shown in Table S3; excitation at $480-546 \mathrm{~nm}$ gives an emission at $479-540 \mathrm{~nm}$, assigned to $\pi-\pi^{*}$ intraligand fluorescence. It is interesting that the complexes show a higher intensity than that of the free ligand. This is supported from their calculated quantum yield values with reference to quinine sulfate. Metal ions can enhance or quench the fluorescence emission of some Schiff base ligands containing an aromatic ring. Quenching of fluorescence of a ligand by transition metal ions during complexation is a rather common phenomenon which is explained by processes such as magnetic perturbation, redox activity, and electronic energy transfer.

Enhancement of fluorescence through complexation is, however, of much interest as it opens up the opportunity for photochemical applications of these complexes [42]. In the absence of metal ions the fluorescence of the ligand is probably quenched by the occurrence of a photoinduced electron transfer (PET) process due to the presence of lone pairs of electrons of the donor atoms in the ligand. Such a PET process is prevented by the complexation of ligand with metal ions; thus the fluorescence intensity may be greatly enhanced by the coordination of metals. The chelation of the ligand to metals increases the rigidity of the ligand and thus reduces the loss of energy by thermal vibrational decay [43]. The emission and excitation spectra of the metal complexes are depicted in Figures 5(a) and 5(b).

3.9. Solvatochromic Behavior. Absorption properties of the ligand were further investigated by recording spectra in solvents of various polarities to elucidate any solvatochromic effect, as it has been accepted that the electronic transitions of azo-azomethine ligands strongly depend on the nature of media [44]. For this purpose organic solvents of a different polarity, namely, DMF, DMSO, THF, dichloromethane and chloroform at a concentration of approximately $10^{-3} \mathrm{M}$ were 

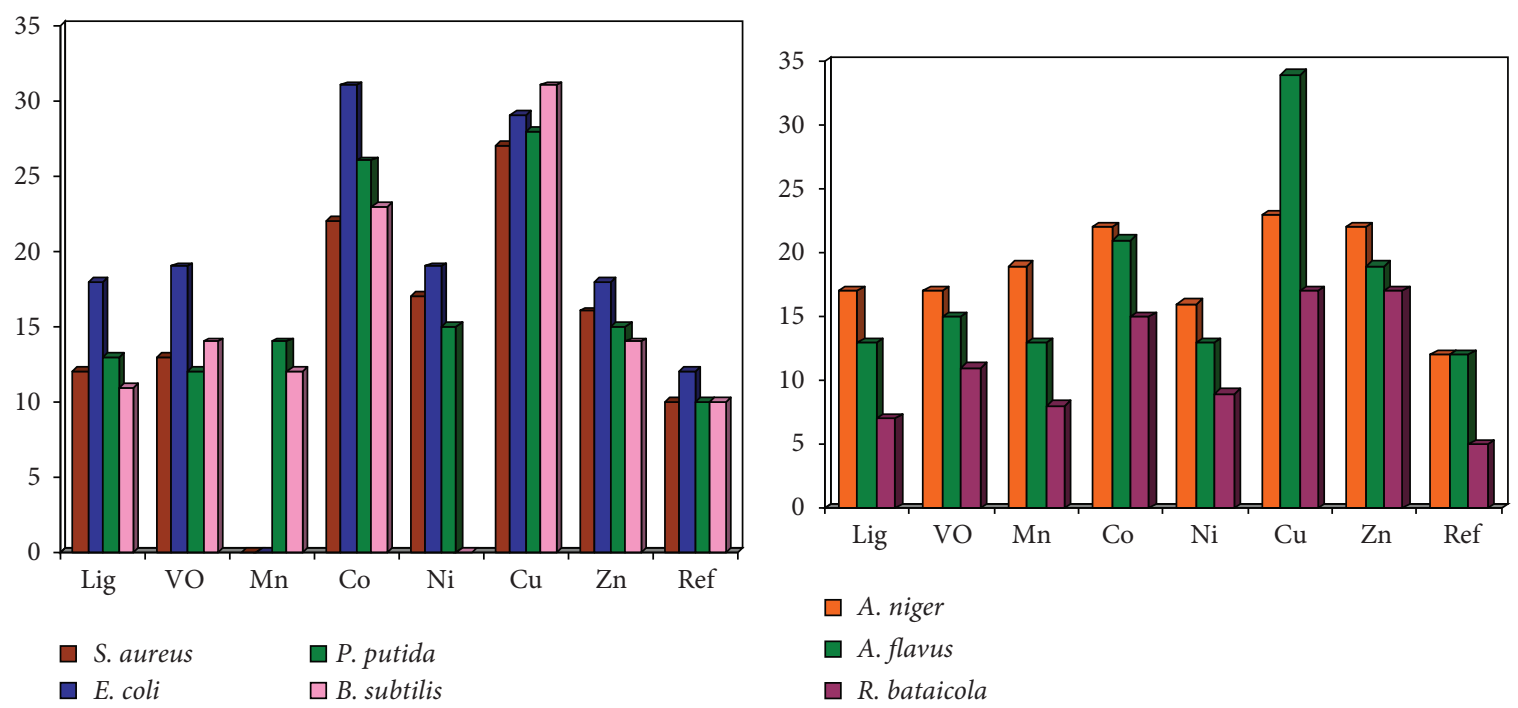

(a)

(b)
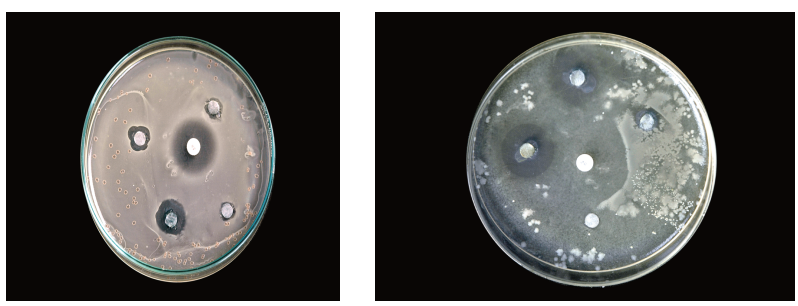

(c)

Figure 4: (a) Biospectrum of the ligand and its complexes for antibacterial activity. (b) Biospectrum of the ligand and its complexes for antifungal activity. (c) The inhibition zones formed for Pseudomonas putida and Aspergillus niger.

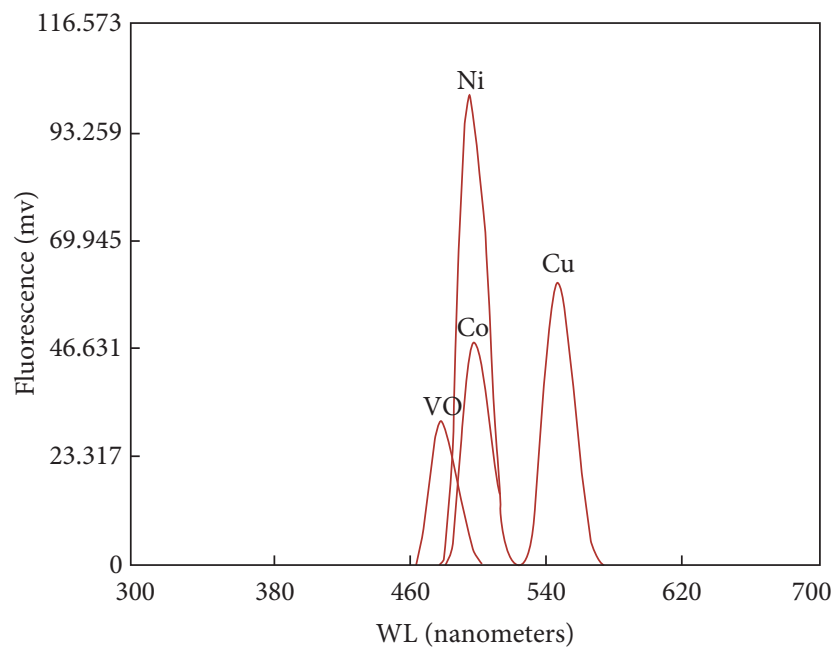

(a)

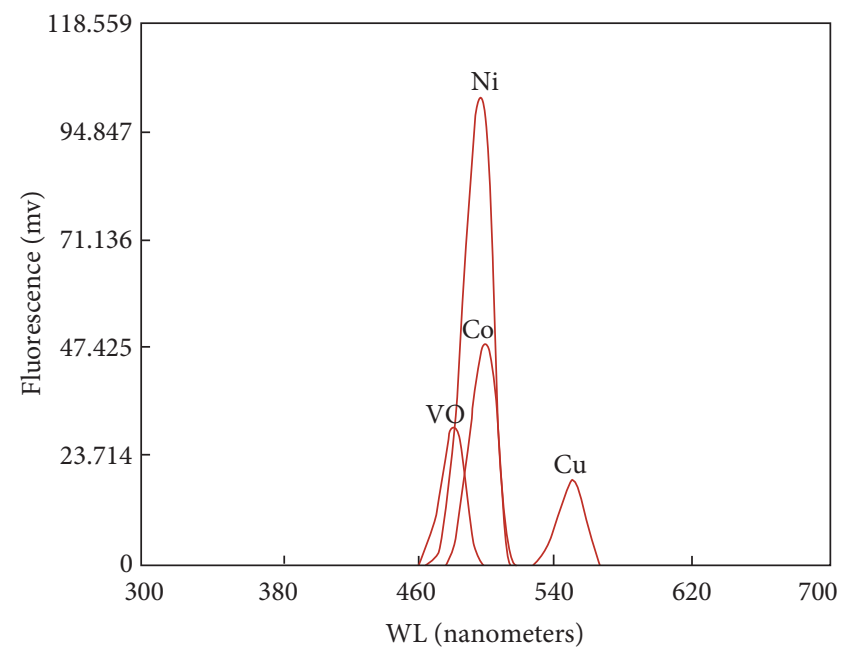

(b)

FIGURE 5: (a) Emission and (b) excitation spectra of metal(II) complexes.

used. The absorption curves of the ligand in various solvents are shown in Figure 6. We found that the absorption band at 295-398 nm generally shows strong bathochromic shift (positive solvatochromism) as the polarity of solvent was increased. The influence of solvents for the prepared azo compound increases in the order DMSO $(395 \mathrm{~nm})>\mathrm{DMF}$ $(368 \mathrm{~nm})>\operatorname{THF}(322 \mathrm{~nm})>\mathrm{CH}_{2} \mathrm{Cl}_{2}(311 \mathrm{~nm})>\mathrm{CHCl}_{3}$ $(272 \mathrm{~nm})$. This observed behavior is accounted as that the prepared azo compound in the ground state and in the excitation state indicate different polarities. This positive 


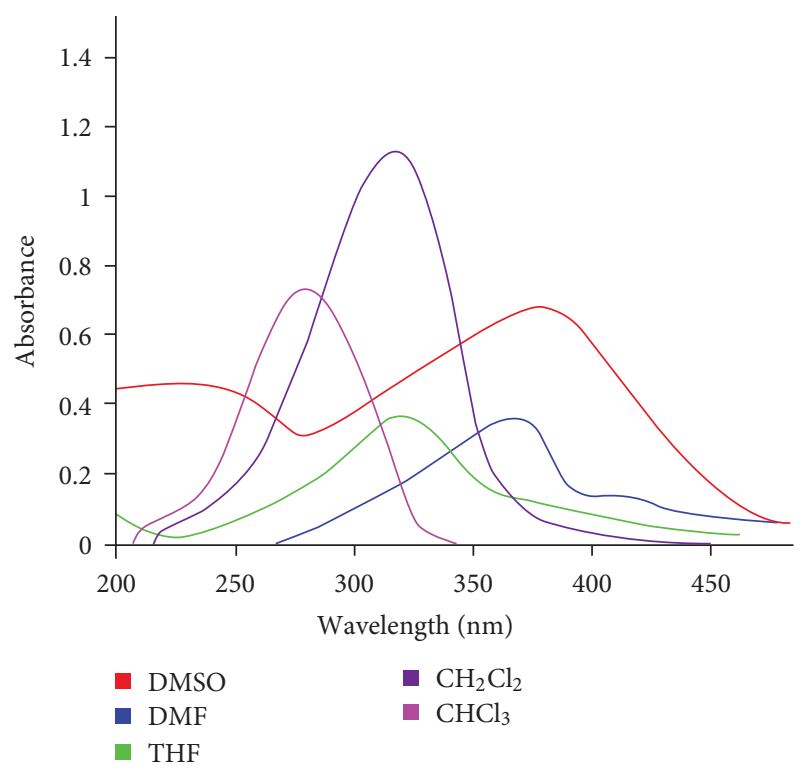

FIgURE 6: Absorption spectra of CDHBDMN in various organic solvents.

solvatochromism exhibited by the compound may be due to the effect of dipole moment changes of the excited state, changes in the hydrogen bonding strength, and/or due to excited state protonation [45]. Furthermore, in the present case the presence of electron withdrawing $-\mathrm{C} \equiv \mathrm{N}$ group in addition to the $\mathrm{Cl}$ atom may influence the absorption characteristics of the azo compound.

3.10. Nonlinear Optical Properties. The SHG (second harmonic generation) efficiency of the azo Schiff base ligand CDHBDMN was determined by modified version of powder technique developed by Kurtz and Perry [46]. The efficiency of the sample was compared with microcrystalline powder of $\mathrm{KDP}$ and urea. The input energy used in this particular setup is $2.2 \mathrm{~mJ} /$ pulse. The experimental data infers that the ligand shows one fourth of the activity of urea and 0.5 times more active than KDP. Though the present investigated azo Schiff base ligand CDHBDMN possesses a pathway of $\pi$-conjugated electrons, the NLO activity is low and this may be due to the absence of electron-pull and electron-push substituents on the benzene rings. The presence of electron acceptor group, that is, chlorine on both sides of the azo compound causes reduction in second-order nonlinearity. Hence, we can conclude that the substituents play an important role in charge transfer through the molecule, and therefore it seems that the substituents require a special attention in designing the azo Schiff base ligands for nonlinear optical properties.

3.11. Scanning Electron Microscopy (SEM). Scanning electron microscope is used here to investigate the surface morphology and particle size of the azo Schiff base CDHBDMN. SEM of CDHBDMN reveals a brittle, glassy, and crystalline structure. Layers in the micrograph reveal that the system contains atoms in a well-defined pattern; thus reactants have

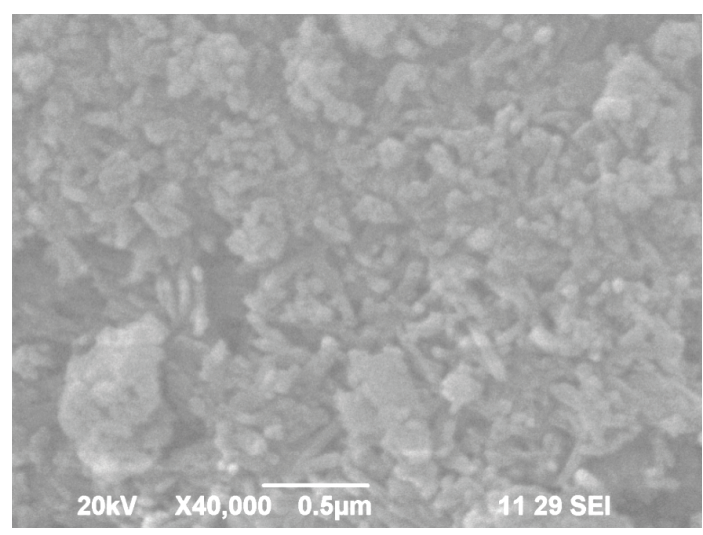

Figure 7: SEM image of [Cu(CDHBDMN)].

reacted completely to form a clear homogenous compound. In general, the SEM photograph shows single phase formation with well-defined grain like shape and particle size in the range of $0.5 \mu \mathrm{m}$. The SEM image of the copper(II) complex is depicted in Figure 7.

\section{Conclusions}

The VO(II), Mn(II), Co(II), Ni(II), $\mathrm{Cu}(\mathrm{II})$, and $\mathrm{Zn}$ (II) azo Schiff base complexes were prepared and characterized using different analytical techniques. Electronic spectral data and magnetic susceptibility measurements support octahedral geometry for $\mathrm{Ni}(\mathrm{II})$, square pyramidal geometry for $\mathrm{VO}(\mathrm{II})$, and square planar geometry for other complexes. Cyclic voltammetry of $\mathrm{Cu}(\mathrm{II})$ complex exhibits irreversible electron transfer process. All the complexes show antimicrobial activity, and the presence of an electron-withdrawing group enhances the antimicrobial activities. The presence of electron acceptor group, that is, chlorine on both the sides of the azo compound causes reduction in second-order nonlinearity. Hence, the present study demonstrated that that the substituents require a special attention in designing the azo Schiff base ligands for nonlinear optical properties. The presence of the azo and azomethine moiety can give rise to photochromism, and this phenomenon will make the new complexes favorable to be used in the fluorescence switches and sensors. The surface morphology studied using SEM showed the well-defined crystallite size of $0.5 \mu \mathrm{m}$. The solvatochromic behaviors infer that, due to the presence of electron-accepting, $-\mathrm{Cl}$ and $-\mathrm{C} \equiv \mathrm{N}$ groups, the $\lambda_{\max }$ was shifted bathochromic in all solvents used.

\section{Acknowledgments}

C. D. Sheela thanks the Management of The American College, Madurai, thanks the Defence Research and Development Organization (DRDO), New Delhi, for providing financial support, and SAIF, IIT, Bombay, SAIF, and CDRI, Lucknow, for analytical facilities. 


\section{References}

[1] L. J. Boucher and C. G. Coe, "Manganese-Schiff base complexes. VI. Synthesis and spectroscopy of aquo[N,N'eth-yl-ene-bis(4-sec-butylsalicylaldiminato)] manganese(III) perchlorate and .mu.-dioxo-bis[N,N'-ethylenebis(4-sec-butylsalicylaldiminato)]dimanganese(IV) and related $\mathrm{N}, \mathrm{N}^{\prime}$ trimethylenebis(4-sec-butylsalicylaldimine) complexes," Inorganic Chemistry, vol. 14, no. 6, pp. 1289-1294, 1975.

[2] A. R. Oki and D. J. Hodgson, "Synthesis, characterization and catalytic properties of manganese(III) Schiff-Base complexes," Inorganica Chimica Acta, vol. 170, pp. 65-73, 1990.

[3] P. Mukherjee, M. G. B. Drew, M. Estrader, C. Diaz, and A. Ghosh, "Influence of counter anions on the structures and magnetic properties of trinuclear $\mathrm{Cu}$ (II) complexes containing a $\mu_{3}-\mathrm{OH}$ core and Schiff base ligands," Inorganica Chimica Acta, vol. 361, no. 1, pp. 161-172, 2008.

[4] B. Ortiz and S. M. Park, "Electrochemical and spectroelectrochemical studies of cobalt salen and salophen as oxygen reduction catalysts," Bulletin of the Korean Chemical Society, vol. 21, no. 4, pp. 405-411, 2000.

[5] E. Ispir, M. Kurtoglu, F. Purtas, and S. Serin, "Synthesis and antimicrobial activity of new schiff bases having the SiOR group ( $\mathrm{R}=\mathrm{CH}$ (3) or $\mathrm{CH} 2 \mathrm{CH} 3$ ), and their transition metal complexes," Transition Metal Chemistry, vol. 30, pp. 1042-1047, 2005.

[6] S. Sreedaran, K. S. Bharathi, A. K. Rahiman et al., "Synthesis, electrochemical, catalytic and antimicrobial activities of novel unsymmetrical macrocyclic dicompartmental binuclear nickel(II) complexes," Polyhedron, vol. 27, no. 7, pp. 1867-1874, 2008.

[7] A. Al-Azmi, A. Z. A. Elassar, and B. L. Booth, "The chemistry of diaminomaleonitrile and its utility in heterocyclic synthesis," Tetrahedron, vol. 59, no. 16, pp. 2749-2763, 2003.

[8] K. Shirai, M. Matsuoka, and K. Fukunishi, "New syntheses and solid state fluorescence of azomethine dyes derived from diaminomaleonitrile and 2,5-diamino-3,6-dicyanopyrazine," Dyes and Pigments, vol. 47, no. 1-2, pp. 107-115, 2000.

[9] E. S. Aazam, M. M. Ghoneim, and M. A. El-Attar, "Synthesis, characterization, electrochemical behavior, and biological activity of bisazomethine dye derived from 2,3diaminomaleonitrile and 2-hydroxy-1-naphthaldehyde and its zinc complex," Journal of Coordination Chemistry, vol. 64, no. 14, pp. 2506-2520, 2011.

[10] V. V. Nesterov, M. Y. Antipin, V. N. Nesterov, B. G. Penn, D. O. Frazier, and T. V. Timofeeva, "Thermally stable imines as new potential nonlinear optical materials," Crystal Growth and Design, vol. 4, no. 3, pp. 521-531, 2004.

[11] S. H. Kim, S. H. Yoon, S. H. Kim, and E. M. Han, "Red electroluminescent azomethine dyes derived from diaminomaleonitrile," Dyes and Pigments, vol. 64, no. 1, pp. 45-48, 2005.

[12] M. J. Maclachlan, M. K. Park, and L. K. Thompson, "Coordination compounds of Schiff-Base ligands derived from diaminomaleonitrile (DMN): mononuclear, dinuclear, and macrocyclic derivatives," Inorganic Chemistry, vol. 35, pp. 5492-5499, 2004.

[13] V. Arun, P. P. Robinson, S. Manju et al., "A novel fluorescent bisazomethine dye derived from 3-hydroxyquinoxaline2-carboxaldehyde and 2,3-diaminomaleonitrile," Dyes and Pigments, vol. 82, no. 3, pp. 268-275, 2009.
[14] M. Rajasekar, S. Sreedaran, R. Prabu et al., "Synthesis, characterization, and antimicrobial activities of nickel(II) and copper(II) Schiff-base complexes," Journal of Coordination Chemistry, vol. 63, no. 1, pp. 136-146, 2010.

[15] M. Badea, R. Olar, E. Cristurean et al., "Thermal stability study of some azo-derivatives and their complexes-part 2. New azoderivative pigments and their $\mathrm{Cu}(\mathrm{II})$ complexes," Journal of Thermal Analysis and Calorimetry, vol. 77, no. 3, pp. 815-824, 2004.

[16] Y. Geng, D. Gu, and F. Gan, "Application of novel azo metal thin film in optical recording," Optical Materials, vol. 27, no. 2, pp. 193-197, 2004.

[17] H. Kocaokutgen, M. Gür, M. S. Soylu, and P. Lönnecke, "Spectroscopic, thermal and crystal structure properties of novel (E)-2,6-dimethyl-4-(4-tert-butylphenyldiazenyl)phenyl acrylate dye," Dyes and Pigments, vol. 67, no. 2, pp. 99-103, 2005.

[18] S. Ren, R. Wang, K. Komastu, and P. B. Krause, Journal of Medicinal Chemistry, vol. 45, pp. 410-419, 2002.

[19] M. Tofazzal, H. Tarafder, M. A. Ali et al., "Coordination chemistry and biological activity of two tridentate ONS and NNS Schiff bases derived from S-benzyldithiocarbazate," Transition Metal Chemistry, vol. 25, no. 3, pp. 295-298, 2000.

[20] H. B. Nishihara, "Multi-Mode molecular switching properties and functions of azo-conjugated metal complexes," Bulletin of the Chemical Society of Japan, vol. 77, pp. 407-412, 2004.

[21] A. Weissenburg, E. S. Proskaur, J. A. Riddick, and E. E. Toope, "Organic solvents," in Techniques of Organic Chemistry, Interscience, New York, NY, USA, 3rd edition, 1995.

[22] B. S. Furniss, A. J. Hannaferd, and V. Rogers, Vogel's Textbook of Practical Organic Chemistry, Longman, New York, NY, USA, 4th edition, 1981.

[23] N. M. EI-Metwally, I. M. Gabr, and A. M. Shallaby, "Synthesis and spectroscopic characterization of new mono- and binuclear complexes of some $\mathrm{NH}(1)$ thiosemicarbazides," Journal of Coordination Chemistry, vol. 58, pp. 1154-1162, 2005.

[24] R. C. Maurya and S. Rajput, "Oxovanadium(IV) complexes of bioinorganic and medicinal relevance: synthesis, characterization and 3D molecular modeling and analysis of some oxovanadium(IV) complexes involving the $\mathrm{O}, \mathrm{N}$-donor environment of pyrazolone-based sulfa drug Schiff bases," Journal of Molecular Structure, vol. 687, p. 35, 2004.

[25] D. M. Johnson, S. E. Reybuck, R. G. Lawton, and P. G. Rasmussen, "Condensation of DAMN with conjugated aldehydes and polymerizations of the corresponding imines," Macromolecules, vol. 38, no. 9, pp. 3615-3621, 2005.

[26] A. Rivera, J. Ríos-Motta, and F. León, "Revisiting the reaction between diaminomaleonitrile and aromatic aldehydes: a green chemistry approach," Molecules, vol. 11, no. 11, pp. 858-866, 2006.

[27] M. Tuncel and S. Serin, "Synthesis and characterization of new azo-linked schiff bases and their cobalt(II), copper(II) and nickel(II) complexes," Transition Metal Chemistry, vol. 31, pp. 805-812, 2006.

[28] N. Ramana, L. Mitub, A. Sakthivela, and M. S. S. Pandia, "Studies on DNA cleavage and antimicrobial screening of transition metal complexes of 4-aminoantipyrine derivatives of $\mathrm{N}_{2} \mathrm{O}_{2}$ type," Journal of the Iranian Chemical Society, vol. 6, pp. 738-748, 2009.

[29] M. Shebl, S. M. E. Khalil, S. A. Ahmed, and H. A. A. Medien, "Synthesis, spectroscopic characterization and antimicrobial 
activity of mono-, bi- and tri-nuclear metal complexes of a new Schiff base ligand," Journal of Molecular Structure, vol. 980, no. 1-3, pp. 39-50, 2010.

[30] A. A. Nejo, G. A. Kolawole, and A. O. Nejo, "Synthesis, characterization, antibacterial, and thermal studies of unsymmetrical Schiff-base complexes of cobalt(II)," Journal of Coordination Chemistry, vol. 63, no. 24, pp. 4398-4410, 2010.

[31] T. Rosu, M. Negoiu, S. Pasculescu, E. Pahontu, D. Poirier, and A. Gulea, "Metal-based biologically active agents: synthesis, characterization, antibacterial and antileukemia activity evaluation of $\mathrm{Cu}(\mathrm{II}), \mathrm{V}(\mathrm{IV})$ and $\mathrm{Ni}(\mathrm{II})$ complexes with antipyrine-derived compounds," European Journal of Medicinal Chemistry, vol. 45, no. 2, pp. 774-781, 2010.

[32] N. H. Al-Shaalan, "Synthesis, characterization and biological activities of $\mathrm{Cu}(\mathrm{II}), \mathrm{Co}(\mathrm{II}), \mathrm{Mn}(\mathrm{II}), \mathrm{Fe}(\mathrm{II})$, and $\mathrm{UO}_{2}$ (VI) complexes with a new Schiff Base hydrazone: $o$-hydroxyacetophenone-7-chloro-4-quinoline hydrazone," Molecules, vol. 16, pp. 8629-8645, 2011.

[33] J. R. Anacona, T. Martell, and I. Sanchez, "Metal complexes of a new ligand derived from 2,3-quinoxalinedithiol and 2,6bis(bromomethyl)pyridine," Journal of the Chilean Chemical Society, vol. 50, no. 1, pp. 375-378, 2005.

[34] R. Kannappan, R. Mahalakshmy, T. M. Rajendiran, R. Venkatesan, and P. Sambasiva Rao, "Magnetic, catalytic, EPR and electrochemical studies on binuclear copper(II) complexes derived from 3,4-disubstituted phenol," Proceedings of the Indian Academy of Sciences, vol. 115, no. 1, pp. 1-14, 2003.

[35] A. B. P. Lever, Inorganic Electronic Spectroscopy, Elsevier, New York, NY, USA, 2nd edition, 1985.

[36] D. Azarifar and M. Shaebanzadeh, "Synthesis and characterization of new 3,5-dinaphthyl substituted 2-pyrazolines and study of their antimicrobial activity," Molecules, vol. 7, no. 12, pp. 885-895, 2002.

[37] C. D. Sheela, C. Anitha, P. Tharmaraj, and D. Kodimunthri, "Synthesis, spectral characterization, and antimicrobial studies of metal complexes of the schiff base derived from [4-amino$\mathrm{N}$-guanylbenzene sulfonamide] and salicylaldehyde," Journal of Coordination Chemistry, vol. 63, no. 5, pp. 884-893, 2010.

[38] S. Belaid, A. Landreau, S. Djebbar, O. Benali-Baitich, G. Bouet, and J. P. Bouchara, "Synthesis, characterization and antifungal activity of a series of manganese(II) and copper(II) complexes with ligands derived from reduced $N, N$ $O$-phenylenebis(salicylideneimine)," Journal of Inorganic Biochemistry, vol. 102, no. 1, pp. 63-69, 2008.

[39] N. Dharamaraj, P. Viswanathamurthi, and K. Natarajan, "Ruthenium(II) complexes containing bidentate Schiff bases and their antifungal activity," Transition Metal Chemistry, vol. 26, pp. 105-109, 2001.

[40] Z. N. Tisseh, M. Dabiri, and M. Nobahar, "Catalyst-free synthesis of $N$-rich heterocycles via multi-component reactions," Tetrahedron, vol. 68, pp. 3351-3356, 2012.

[41] Z. H. Chohan, K. M. Khan, and C. T. Supuran, "Synthesis of antibacterial and antifungal cobalt(II), copper(II), nickel(II) and zinc(II) complexes with bis-( $1,1^{\prime}$-disubstituted ferrocenyl)thiocarbohydrazone and bis-( $1,1^{\prime}$-disubstituted ferrocenyl)carbohydrazone," Applied Organometallic Chemistry, vol. 18, pp. 305-310, 2004.

[42] A. Majumder, G. M. Rosair, A. Mallick, N. Chattopadhyay, and S. Mitra, "Synthesis, structures and fluorescence of nickel, zinc and cadmium complexes with the N,N,O-tridentate Schiff base N-2-pyridylmethylidene-2-hydroxy-phenylamine," Polyhedron, vol. 25, no. 8, pp. 1753-1762, 2006.
[43] D. Das, B. G. Chand, K. K. Sarker, J. Dinda, and C. Sinha, " $\mathrm{Zn}(\mathrm{II})$-azide complexes of diimine and azoimine functions: synthesis, spectra and X-ray structures," Polyhedron, vol. 25, no. 11, pp. 2333-2340, 2006.

[44] X. Chen, J. Zhang, H. Zhang et al., "Preparation and nonlinear optical studies of a novel thermal stable polymer containing azo chromophores in the side chain," Dyes and Pigments, vol. 77, no. 1, pp. 223-228, 2008.

[45] H. Khanmohammadi and M. Darvishpour, "New azo ligands containing azomethine groups in the pyridazine-based chain: synthesis and characterization," Dyes and Pigments, vol. 81, no. 3, pp. 167-173, 2009.

[46] S. K. Kurtz and T. T. Perry, "A powder technique for the evaluation of nonlinear optical materials," Journal of Applied Physics, vol. 39, no. 8, pp. 3798-3813, 1968. 

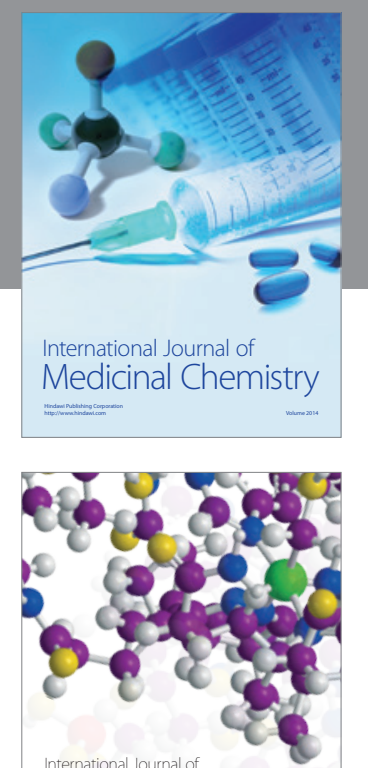

\section{Carbohydrate} Chemistry

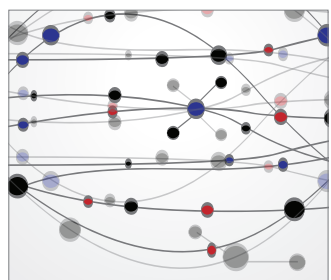

The Scientific World Journal
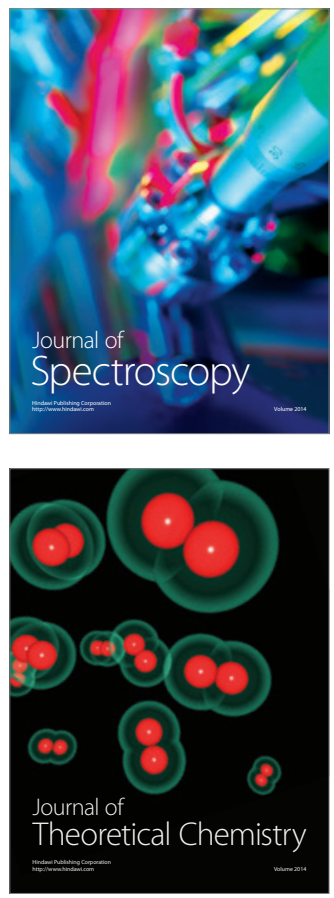
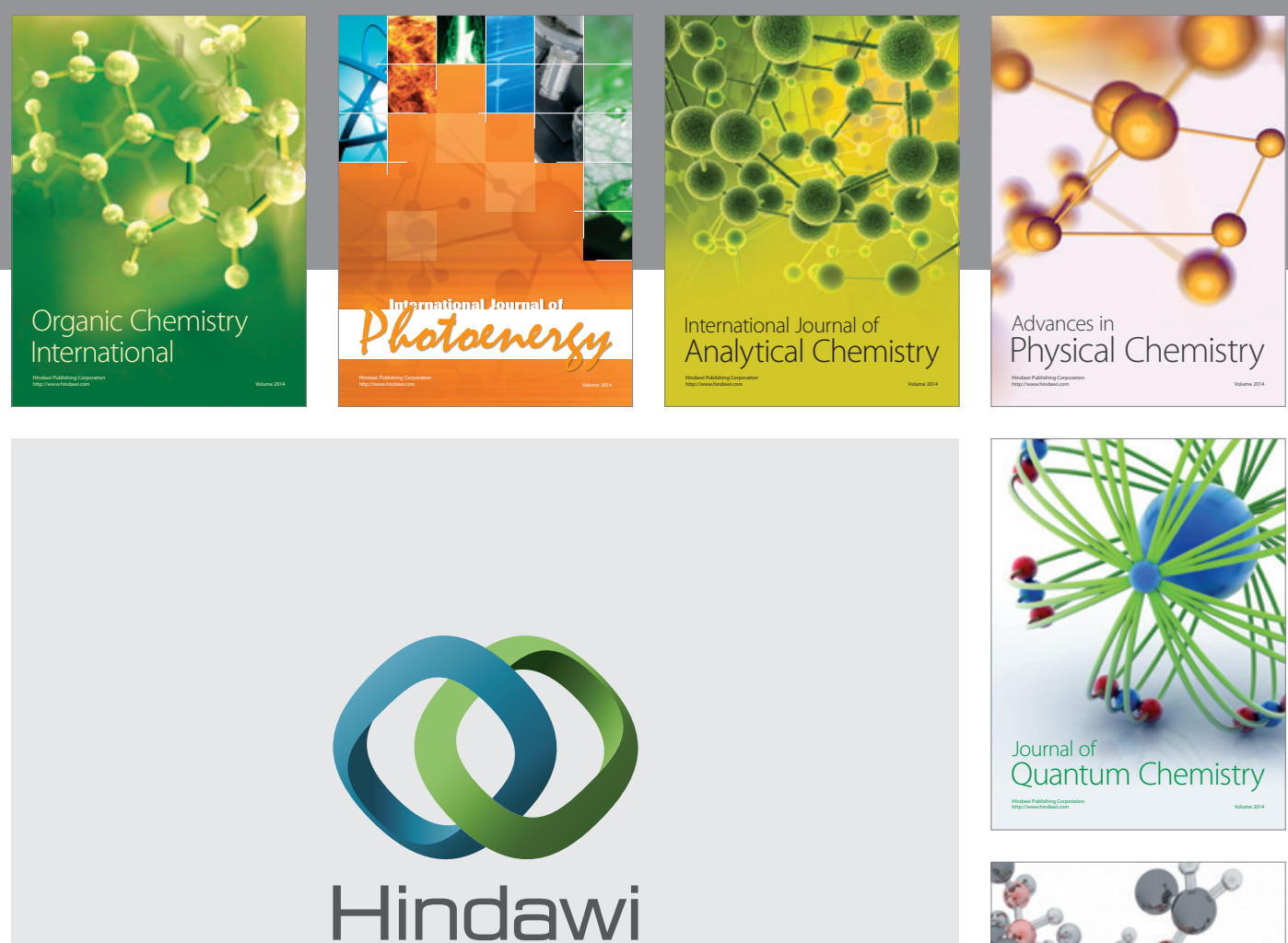

Submit your manuscripts at

http://www.hindawi.com

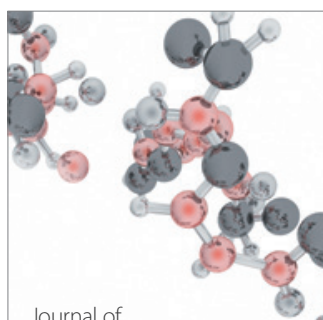

Analytical Methods

in Chemistry

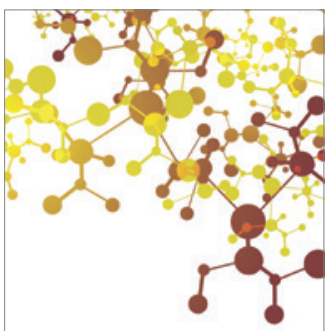

Journal of

Applied Chemistry

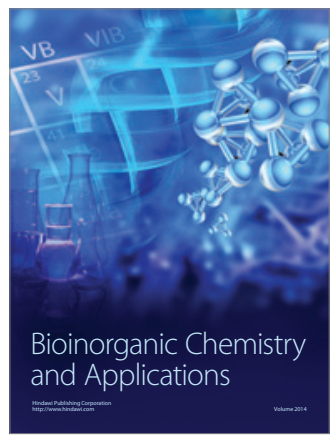

Inorganic Chemistry
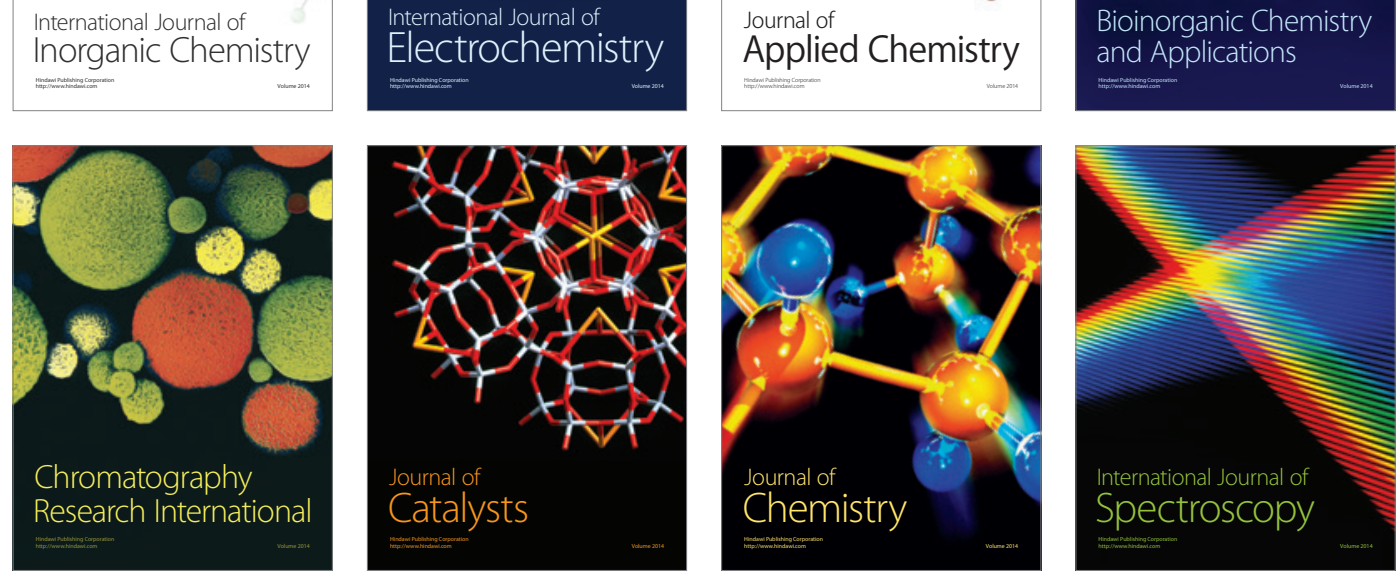